\title{
A Rapid and Quantitative Assay to Estimate Gene Transfer into Retrovirally Transduced Hematopoietic Stem/Progenitor Cells Using a 96-Well Format PCR and Fluorescent Detection System Universal for MMLV-Based Proviruses
}

\author{
CHRISTOPHER J. GERARD, ${ }^{1}$ MARY JO ARBOLEDA, ${ }^{1}$ GREGG SOLAR, ${ }^{1}$ \\ JAMES J. MULÉ, ${ }^{2}$ and WILLIAM G. KERR ${ }^{1}$
}

\begin{abstract}
The polymerase chain reaction (PCR) is an extremely sensitive assay that has many uses im retroviral-mediated gene transfer protocols. Because the majority of retroviral vectors used in current gene transfer protocols are based on the Moloney-murine leukemia virus (MMLV), we have designed primers which amplify a region of the $\Psi$ packaging sequence from all MMLV retroviruses tested. This assay detects gene transfer by all MMLV-based vectors and is especially useful for the laboratory that routinely screens a number of different retroviruses for their gene transfer efficiency. Furthermore, we present here a novel technique for harvesting single colonies derived from hematopoietic stem/progenitor cells growing in methylcellulose medium that expedites and substantially inproves the resulting quantitative estimates of retroviral transduction frequencies. This technique utilizes a conventional 96-well format and, when coupled with a fluorescence-based post-PCR detection system, makes it unnecessary to run agarose gels to visualize the PCR product. This system of PCR product detection, which uses the $5^{\prime} \rightarrow 3^{\prime}$ exonuclease activity of Taq DNA polymerase to cleave a fluorescently labeled probe during each round of PCR amplification, is fast, convemient, and at least as sensitive as an ethidium bromide-based detection system when used in conjunction with our universal PCR assay.
\end{abstract}

\section{OVERVIEW SUMMARY}

The polymerase chain reaction (PCR) analysis of colonies of clonogenic cells growing in methylcellulose medium is a routine procedure to estimate the frequency of retroviral transduction into hematopoietic stem/progenitor cells. This study describes a sensitive assay system that takes advantage of the standard 96-well fornuat to expedite the processing of single methylcellulose colonies. Assay sensitivity is dependent on a PCR primer pair which amplifies a region of the $\Psi$ packaging sequence of all Moloney-based retroviruses tested. Using this primer pair, we present the optimized PCR conditions for the analysis of single colonies of clonogenic cells growing in methylcellulose medium as well as the conditions for a semiquantitative bulk PCR assay to estimate the transduction frequency immediately following the transduction protocol. This PCR primer pair, along with the capability for more rapid screening of hematopoietic stem/progenitor colomies, is especially useful for the laboratory that is screening a number of different retroviral constructions for their transduction efficiency.

\section{INTRODUCTION}

$\mathbf{T}$ HE POLYMERASE CHAIN REACTION (PCR) is an extremely sensitive assay that has many uses in retroviral-mediated gene transfer protocols (Morgan et al., 1990). We routinely use PCR to estimate the frequency of gene transfer following retroviral transduction of hematopoietic stem/progenitor cells. Defining the conditions for maximum sensitivity and specificity of the PCR requires the optimization of several different reaction parameters, including primer concentration, annealing temperature, salt concentration, and magnesium ion concentration (e.g., $\mathrm{KCl}, \mathrm{MgCl}_{2}$ ) (Saiki, 1989). Because our laboratory routinely screens a number of different retroviral vectors for their

${ }^{1}$ Department of Gene Therapy, SyStemix, Inc., Palo Alto, CA 94304.

${ }^{2}$ Department of Surgery, University of Michigan Medical Center, Ann Arbor, MI 48109. 
gene transfer efficiency into hematopoietic stem/progenitor cells, we sought a universal PCR assay that we could apply to a broad range of retroviral vectors.

Because the majority of retroviral vectors used in current gene transfer protocols are based on the Moloney-murine leukemia virus (MMLV) (Miller and Rosman, 1989; Jolly, 1994), we examined the MMLV provirus genome for regions that would be found in most MMLV-based vectors. The $\Psi$ packaging sequence is a 300-350-bp region downstream of the $5^{\prime}$ long terminal repeat (LTR) which extends into the gag coding sequence (Bender et al., 1987). This region is required for efficient packaging of retroviral genomic RNA molecules. In addition, complete inclusion of this region in retroviral vectors has been shown to increase viral titer 5-10-fold (when compared to retroviral vectors that contain $3^{\prime}$ deletions in this region) (Armentano, 1987). We have designed PCR primers that amplify a region of the $\Psi$ packaging sequence from all MMLV retroviral vectors tested (five total), and therefore this assay should find utility as a universal means to detect gene transfer by MMLV-based vectors.

In addition to designing the primers and defining the conditions of a universal PCR assay for MMLV-based proviruses, we have developed a novel technique for high-throughput PCR screening of progeny of hematopoietic stem/progenitor cells growing in methylcellulose medium. This technique, coupled with a fluorescence-based post-PCR detection system, expedites the analysis of methylcellulose colonies for retroviral transduction by taking advantage of the faster processing potential inherent in the 96-well format. Also, because it is based on analysis of single colonies, this method can substantially im- prove the resulting quantitative estimates of transduction frequency. Finally, we demonstrate the utility of the PCR assay described herein by determining the frequency of gene transfer into highly purified human hematopoietic stem cells of the CD $34^{+}$Thy- $1^{+}$Lin $^{-}$phenotype derived from cytokine-mobilized peripheral blood.

\section{MATERIALS AND METHODS}

\section{$\Psi$ universal primers}

Potential primer sites for the $\Psi$ packaging signal were chosen based on: (i) sequence homology across several MMLVbased retroviruses (see Fig. 1), (ii) lack of secondary structure, (iii) $40-60 \%$ GC content, and (iv) melting temperature appropriate for a PCR primer (Rychlik, 1993). Melting temperature $\left(T_{\mathrm{M}}\right)$ was estimated using the following algorithm: ${ }^{\circ} \mathrm{C}=$ (4)(number of $\mathrm{G} / \mathrm{C}$ bases) + (2)(number of $\mathrm{A} / \mathrm{T}$ bases).

\section{Cell lines}

The human acute myelogenous leukemia $\mathrm{CD} 34^{+}$cell line, KG-1a (Koeffler et al., 1980), was used as a negative control for the $\Psi$ primers presented in this report. The KG- $1 \mathrm{a} / \boldsymbol{\beta}$ / cell line (hereafter referred to as $\beta 7$ ) is a KG-1a clone transduced with MFG-lacZ and selected by the FACS-Gal procedure (Nolan et al., 1988). The KG-1a/SV29 cell line (hereafter referred to as SV29) is a KG-1a clone transduced with the MMLV-SV-NLS-lacZ retrovirus which was also cloned via FACS-Gal (Bonnerot et al., 1987). The Sp6- $\gamma$ cell line (Hwu

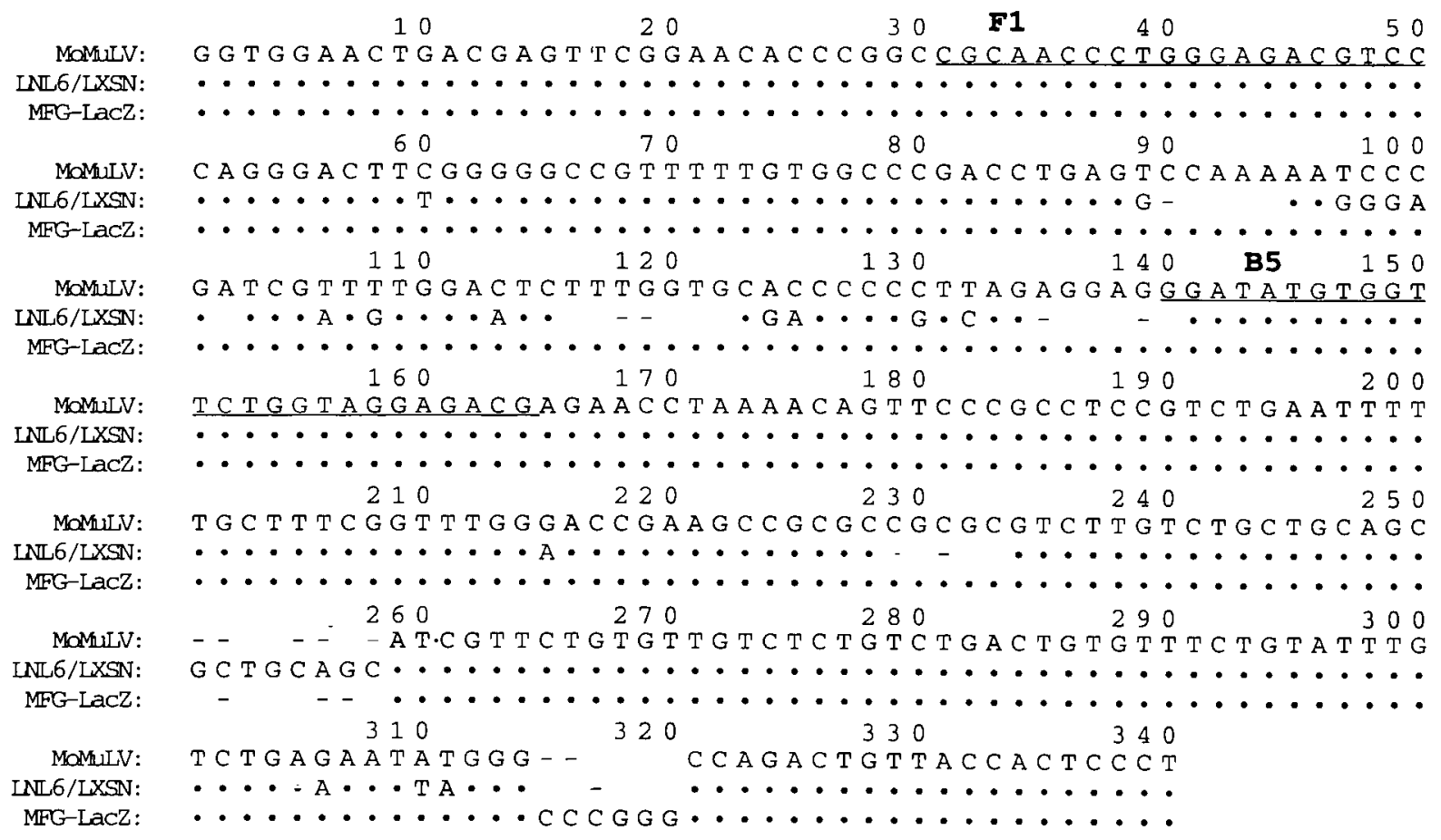

FIG. 1. Sequence comparison of the extended packaging signal $(\Psi)$ of several Moloney-based retroviruses. A dot indicates that the nucleotide is unchanged from the Moloney sequence, and a dash indicates that a nucleotide has been deleted. Nucleotide substitutions are as indicated. Both the upstream primer (F1) and the downstream primer (B5) are underlined. 
et al., 1993) is a producer cell line (PA317) containing the LXSN retroviral vector (Miller and Rosman, 1989), which is a derivative of the LNL6 retroviral vector (Bender et al., 1987).

\section{Cell lysate standards and controls}

Bulk PCR controls were made by adding KG-1a cells ( $\Psi$ negative) to a two-fold dilution series of SV29 cells ( $\Psi$ positive). Lysates A through F contain 10, 5, 2.5, 1.3, 0.6, and 0.3\% SV29 cells, respectively. Lysate $\emptyset$ contains $100 \%$ KG-1a cells. The total number of cell equivalents (including KG-1a cells) per $25 \mu \mathrm{l}$ of lysate is 2,500 .

To determine the level of detection with the $\Psi$ primers when multiple clonogenic colonies growing in methylcellulose are pooled and processed for PCR, $\beta 7$ and KG-1a methylcellulose colonies were pooled and processed according to the following ratio-4:1, 3:2, and $2: 3 \mathrm{KG}-1 \mathrm{a}: \beta 7$ colonies. The five colonies were harvested using a P-10 pipet set at $3.0 \mu$, rinsed in 200 $\mu \mathrm{l}$ of PBS, vortexed, and centrifuged for $30 \mathrm{sec}$ at $10,000 \mathrm{rpm}$ in a benchtop centrifuge (TOMY). PBS was removed and 100 $\mu \mathrm{l}$ of lysing buffer (see below) was added. Samples were incubated for $60 \mathrm{~min}$ at $60^{\circ} \mathrm{C}$, then transferred to a $95^{\circ} \mathrm{C}$ heat block for $10-15 \mathrm{~min}$. One-tenth $(10 \mu \mathrm{l})$ of each lysate was used in the PCR.

To determine if residual methylcellulose has any effect on PCR sensitivity, cell lysates were made that simulate the conditions of a pooled clonogenic methylcellulose colony assay using $\beta 7$ cells ( $\Psi$ positive) in a background of KG-la cells ( $\Psi$ negative), with and without the addition of methylcellulose medium. Duplicate sets of standards were made up which included 500,250 , and $50 \beta 7$ cells per 1,500 KG-1a cells in 200 $\mu \mathrm{l}$ of PBS; $15 \mu \mathrm{l}$ of methylcellulose media was added to one set of standards after the colonies were picked but before the PBS was replaced with PCR lysing buffer. All samples were then processed as above. One-fourth $(25 \mu \mathrm{l})$ of each lysate was used in the PCR.

\section{PCR conditions}

All PCRs were conducted in a total volume of $25-28 \mu \mathrm{l}$ using the Perkin Elmer/Applied Biosystems 9600 thermal cycler. Unless otherwise stated, the 40-cycle PCR is as follows: initial denaturation of $30 \mathrm{sec}$ at $95^{\circ} \mathrm{C}$ followed by 40 cycles of $10 \mathrm{sec}$ denaturation at $95^{\circ} \mathrm{C}, 15 \mathrm{sec}$ annealing at $64^{\circ} \mathrm{C}$, and $15 \mathrm{sec} \mathrm{ex}-$ tension at $72^{\circ} \mathrm{C}$. The protocol finishes with a final 5-min extension at $72^{\circ} \mathrm{C}$ and a $4^{\circ} \mathrm{C}$ soak, PCR product was visualized by loading $15 \mu \mathrm{l}$ on a $4 \%$ NuSieve 3:1 agarose gel (FMC Bioproducts) containing ethidium bromide (Sigma). Images were captured with either a Polaroid camera or the Eagle Eye II Still Video System (Stratagene).

The exploratory PCR analyses of potential $\Psi$ primer combinations were conducted using an annealing temperature of $55^{\circ} \mathrm{C}$ under the following conditions: $20 \mathrm{mM}$ Tris $\mathrm{pH} 8.3,50$ $\mathrm{m} M \mathrm{KCl}, 1.5 \mathrm{~m} M \mathrm{MgCl}_{2}, 0.2 \mathrm{~m} M$ each dNTP (Boehringer Mannheim), $0.35 \mu M \Psi$ primers, and 1.0 units $/ 25-\mu 1$ reaction of AmpliTaq DNA polymerase (Perkin Elmer/Applied Biosystems. Optimal PCR buffer conditions were determined using the Opti-prime PCR optimization kit (Stratagene). In addition, optimum primer concentration was determined by standard titration experiments. The final concentration of the PCR components for the optimized conditions are as follows: $10 \mathrm{mM}$
Tris pH 9.2, $75 \mathrm{~m} M \mathrm{KCl}, 1.5 \mathrm{~m} M \mathrm{MgCl}_{2}, 0.2 \mathrm{~m} M$ each dNTP (Boehringer Mannheim), $0.20 \mu M \Psi$ primers, $0.5 \mu M$ T4 gene 32 protein (Boehringer Mannheim), and 1.0 units/25- $\mu$ l reaction of AmpliTaq DNA polymerase. When $\Psi$ primers were multiplexed with primers that amplify a region of the human $\beta$-globin sequence, these primers were used at a concentration of 0.16 $\mu M$ (BG1, 5'-CAA-CTT-CAT-CCA-CGT-TCA-CC-3'; BG2, 5'-GAA-GAG-CCA-AGG-ACA-GGT-AC-3'). With the exception of the $\Psi$ primers used in the initial matrix analysis, all PCR primers were HPLC purified. PCR cell lysing buffer consists of $1 \times$ PCR buffer (as above) with the addition of $0.5 \%$ NP-40 (Sigma), $0.5 \%$ Tween-20 (Sigma), and $0.91 \mathrm{mg} / \mathrm{ml}$ of proteinase $\mathrm{K}$ (Boehringer Mannheim).

\section{Hybridization assay}

DNA from agarose gels was transferred to Zeta-Probe GT blotting membranes (Bio-Rad) in 20× SSPE and hybridized overnight at $68^{\circ} \mathrm{C}$ with the $\Psi$ product oligonucleotide probe BK29 (5' -CTT-CGG-GGG-CCG-TTT-TTG-TGG-CCC-GACCT $\left.-3^{\prime}\right)$ that was end-labeled with [ $\gamma^{32}$ P]ATP using standard protocols (Sambrook et al., 1989). Blots were rinsed briefly in $2 \times$ SSPE/0.1\% SDS, followed by $2 \times 30$-minute washes at $68^{\circ} \mathrm{C}$ in $0.1 \times \mathrm{SSPE} / 0.1 \% \mathrm{SDS}$, and then exposed for $18 \mathrm{hr}$ to a phosphor screen (Molecular Dynamics).

\section{Direct lysate PCR from single methylcellulose colonies in a 96-well format}

A repeating pipetter was used to fill 0.2 -ml thin-walled PCR tubes with $50 \mu \mathrm{l}$ of cell lysing buffer (see above). Tubes are held in a 96-well format by a MicroAmp tray/retainer assembly (Perkin Elmer/Applied Biosystems). Single clonogenic colonies growing in methylcellulose were harvested using a P10 pipet set at $3.0 \mu \mathrm{l}$ and placed directly into the tubes containing cell lysing buffer; while picking colonies the tubes were kept on ice. Several tubes, or wells, were reserved for PCR and/or transduction controls (e.g., mock-transduced colonies), and at least one tube contained lysing buffer only as a negative template control. The plate was then covered and transferred to either a specially designed heating block (USA Scientific Plastics) or a thermal cycler (PE 9600, Perkin Elmer/Applied Biosystems) where it was incubated for $1 \mathrm{hr}$ at $60^{\circ} \mathrm{C}$, followed by a 5 -min incubation at $95^{\circ} \mathrm{C}(10 \mathrm{~min}$ if heating block is used $)$.

Following the cell lysis procedure, lysates were transferred to a second plate containing the PCR master mix. (The appropriate single-target or multiplex PCR master mix can be aliquoted into each well of a fresh 96-well plate, before the addition of the methylcellulose colony lysate, using a repeating pipetter.) The cell lysate is efficiently transferred to the tubes containing the PCR master mix (on ice) using a multichannel pipetter and filter barrier pipet tips to prevent aerosol contamination. Once all lysates were transferred to the second plate, and the appropriate PCR controls added, the tubes were covered and the plate transferred to the thermal cycler for amplification.

\section{Experimental transduction}

One hundred thousand $\mathrm{CD} 34^{+}$Thy- $1^{+} \mathrm{Lin}^{-}$stem/progenitor cells were sorted from cytokine-mobilized human periph- 
eral blood (FACStar Plus, Becton Dickinson) and incubated with $1.0 \mathrm{ml}$ of retroviral (Moloney-based LMTNL vector) supernatant (DMEM media harvested from retroviral producer cells; moi $=50$ ) containing $50 \mathrm{ng} / \mathrm{ml} \mathrm{LIF,} 25 \mathrm{ng} / \mathrm{ml} \mathrm{IL-3,} 50$ $\mathrm{ng} / \mathrm{ml}$ IL-6, and $4 \mu \mathrm{g} / \mathrm{ml}$ protamine sulfate (LIF, IL-3, IL-6 supplied by Sandoz Pharmaceuticals protamine sulfate, Sigma Chemical Co.). For the mock transduction, cells were incubated in Dulbecco modified Eagle medium (DMEM) supplemented with $10 \%$ fetal calf serum (Hyclone Laboratories), $50 \mathrm{U} / \mathrm{ml}$ penicillin (JRH Biosciences), $50 \mu \mathrm{g} / \mathrm{ml}$ streptomycin (JRH Biosciences), $2 \mathrm{~m} M$ L-glutamine (JRH Biosciences), and the growth factors at the concentrations mentioned above. Cells were pelleted and fresh supernatant (or DMEM complete) was added after 24 and $48 \mathrm{hr}$. Transduction was terminated after 72 $\mathrm{hr}$ and cells were resuspended in PBS containing 1\% human serum albumin (alpha-Therapeutic Corp.), at which point $2.5 \times$ $10^{3}$ cells were added to $5 \mathrm{ml}$ of methylcellulose medium $(80 \%$ MethoCult H4230, Stem Cell Technologies) containing the following cytokines: $10 \mathrm{ng} / \mathrm{ml} \mathrm{c}-k i t$ ligand (R\&D Systems), 25 $\mathrm{ng} / \mathrm{ml}$ of granulocyte-macrophage colony-stimulating factor (GM-CSF) (Sandoz Pharm.), $25 \mathrm{ng} / \mathrm{ml}$ of granulocyte colonystimulating factor (G-CSF) (Amgen), $10 \mathrm{ng} / \mathrm{ml}$ of IL-2 (Sandoz Pharm.), and $1.2 \mathrm{U} / \mathrm{ml}$ of recombinant human erythropoietin (rhEPO) (R\&D Systems). Cells were plated in four $35 \times 10$ $\mathrm{mm}$ tissue culture dishes at $1.1 \mathrm{~mL} /$ dish (Nunc, Inc.) and incubated at $37^{\circ} \mathrm{C} / 5.0 \% \mathrm{CO}_{2}$ for 14 days, after which single hematopoietic colonies were picked according to the protocol above and one-fifth $(10 \mu \mathrm{l})$ of the lysate from an individual colony was amplified using the F1/B5 $\Psi$ primers.

\section{TaqMan* fluorescence-based post-PCR detection assay}

Single colonies of clonogenic cells from an experimental transduction were picked according to the protocol above and $10 \mu \mathrm{l}$ of the lysate from an individual colony was amplified as above except that a 24 -mer oligonucleotide probe $\left(5^{\prime}\right.$-CCGTTT-TTG-TGG-CCC-GAC-CTG-AGT-3'), internal to the F1/B5 $\Psi$ PCR product, was included in the PCR master mix at a final concentration of $0.2 \mu M$, and the total reaction volume was increased to $60 \mu \mathrm{l}$. The $24-\mathrm{mer}$ fluorescent probe (synthesized by Perkin-Elmer Corporation) was labeled at the $5^{\prime}$ end with the reporter dye molecule, TET (6-carboxy-tetrachlorofluorescein; emission $\lambda 538 \mathrm{~nm}$ ), while the quencher dye molecule, TAMRA (6-carboxytetramethyl-rodamine; emission $\lambda$ $582 \mathrm{~nm}$ ), was added to the $3^{\prime}$ end of the probe via a linker arm nucleotide (LAN). A phosphate was added to the $3^{\prime}$ end to prevent extension of the probe during the PCR. During each cycle of the PCR the $5^{\prime} \rightarrow 3^{\prime}$ exonuclease activity of Thermus aquaticus DNA polymerase cleaves the probe (Holland et al., 1991; Lee et al., 1993), thereby increasing the fluorescence of the reporter dye at the appropriate wavelength. The increase in fluorescence is proportional to the concentration of template in the PCR.

Following the standard PCR thermal cycler protocol, $10 \mu \mathrm{l}$ of the reaction was visualized on a $4 \%$ agarose gel containing ethidium bromide (as above). The 96-sample tray/retainer assembly, containing the remaining reaction volume, was transInc.

*TaqMan is a registered trademark of Roche Molecular Systems, ferred to the LS-50B luminescence spectrometer plate reader (Perkin-Elmer Corporation), the fluorescence emission (at 488 $\mathrm{nm}$ excitation $\lambda$ ) of both the reporter and quencher dye was measured and the ratio, RQ for each sample (emission intensity of reporter dye divided by the emission intensity of the quencher dye) was calculated. The TaqMan software then calculated the $\triangle R Q$ for each sample: $\triangle R Q=R^{+}$(PCR with target template) minus $\mathrm{RQ}^{-}$(PCR without target template). A positive result is determined as any value greater than the threshold $\Delta R Q$. The threshold $\Delta R Q$ is determined by calculating both the mean and standard deviation of the Reporter:Quencher ratios for all no template controls $\left(\mathrm{RQ}^{-}\right)$and then multiplying the standard deviation by a multiplier as determined by a table of student's $t$-distribution values. When 10 no-template controls (mock-transduced colonies) are analyzed per plate, the standard deviation of the Reporter:Quencher ratio is multiplied by 4.781 to achieve the $\triangle \mathrm{RQ}$ threshold above which all samples have a $99.95 \%$ confidence level of being a positive result. In addition, if the fluorescence of the quencher molecule for any one sample is less than the mean quencher fluorescence of the no-template controls, then that sample is tagged with a low signal warning so as to alert the investigator to a potentially invalid Reporter:Quencher ratio.

\section{RESULTS}

\section{$\Psi$ universal primers}

Table 1 shows the sequence and position of the 8 possible $\Psi$ primers-3 upstream and 5 downstream oligonucleotides. Their position is referenced according to the $\Psi$ extended packaging signal of the MMLV (Fig. 1). Ideally, a primer pair universal for all three retroviral backbones investigated would produce a band of the expected size with little or no spurious background bands; by comparison, the KG-1a cell lysate should be free of the expected PCR product. The four possible outcomes for each primer combination in the initial matrix analysis of all $15 \Psi$ primers are shown in Fig. 2: XP, excessive nonspecific product formation; IP, insufficient product formation; NP, no product with an LNL6-based vector; and OK, specific product formation of the expected size, with little or no nonspecific products. This initial PCR was conducted at an annealing temperature of $55^{\circ} \mathrm{C}$ to permit maximum primer-template annealing. An example of each outcome is shown in Fig. 2 where lanes $1-4$ represent 250 cell equivalents of the five cell lysates as described above: $\beta 7$ ( $\Psi$ positive), KG-la ( $\Psi$ negative), SV29 ( $\Psi$ positive), and Sp6- $\gamma(\Psi$ positive), respectively; - is a negative PCR buffer control. For each example, an arrow indicates the projected position of the $\Psi$ packaging sequence PCR product (as based on the sequence data in Fig. 1).

Many of the primer combinations in Fig. 2 produced a high degree of nonspecific bands, potentially the result of the low annealing temperature. However, even with the less stringent conditions of this initial PCR, it was evident that several of the combinations, specifically F1/B5 and F2/B5, were good candidates for a universal primer pair. The PCR product resulting from the Sp6- $\gamma$ cell lysate (Fig. 2, lane 4) was slightly smaller in size than the similarly targeted region in the $\beta 7$ or SV29 cell lines (115 bp versus $134 \mathrm{bp}$, respectively). The smaller prod- 
Table 1. PCR Primers Used to Amplify a Region in the $\Psi$ Packaging Signal

\begin{tabular}{cccc}
\hline PCR Primers & Sequence $\left(5^{\prime} \rightarrow 3^{\prime}\right)$ & Position $^{\star}$ & $T_{M}\left({ }^{\circ} \mathrm{C}\right)^{\star \star}$ \\
\hline Upstream (sense): & & \\
F1 & CgCAACCCTgggAgACgTCC & $31-50$ & 68 \\
F2 & gAACACCCggCCgCAACCCTg & $20-40$ & 72 \\
F3 & gCCCgACCTgAgTCCAAAAATC & $77-98$ & 68 \\
Downstream (anti-sense): & & \\
B1 & ggCgCggCTTCggTCCCAAAC & $209-229$ & 72 \\
B2 & gCAgCAgACAAgACgCgCggC & $227-247$ & 72 \\
B3 & CCTACCAgACCACATATCCCTCC & 136159 & 74 \\
B4 & CAAAAATTCAgACggAggCggg & $181-202$ & 68 \\
B5 & CgTCTCCTACCAgAACCACATATCC & $140-164$ & 76 \\
\hline
\end{tabular}

*All sequences are referenced according to the sense strand. Position based on the sequence of the $\Psi$ extended packaging signal of the Moloney-murine leukemia virus (MMLV; see Fig. 1).

**Melting temperature: ${ }^{\circ} \mathrm{C}=(4)$ (number of $\mathrm{G} / \mathrm{C}$ bases $)+(2)$ (number of $\mathrm{A} / \mathrm{T}$ bases).

uct is a consequence of a number of small deletions in the amplified region of the LNL6/LXSN backbone (see Fig. 1).

Primer combinations using F3 as the upstream primer, although they produced the expected PCR product with the $\beta 7$ and SV29 cell lysates, did not produce a target-specific band with Sp6- $\gamma / \mathrm{KG}-1$ a cell lysates. The vector used in the Sp6- $\gamma$ producer cell line (LXSN) is based on the LNL6 vector. According to Fig. 1, the F3 primer has a 2-nucleotide mismatch with the LNL6 vector sequence at the crucial $3^{\prime}$ end of the oligonucleotide, and this difference most likely prevents annealing and extension of the target in the Sp6- $\gamma$ cell lysate.

Ten of the most promising primer combinations from the initial PCR, according to the criteria presented above, were tested in a second PCR with an increase in the annealing temperature to $62^{\circ} \mathrm{C}$. The increased annealing temperature substantially reduced the incidence and intensity of nonspecific background bands. Two particular primer combinations, F1/B5 and F2/B5, produced very strong target-specific PCR products. However, the F2/B5 primer combination still produced two faint nonspecific bands in the KG-1a cell lysate ( $\sim 200$ and $600 \mathrm{bp}$; data not shown). A primer titration experiment was conducted with both primer pairs and it was determined that the incidence of nonspecific bands could be eliminated without having a negative impact on product formation by using the primers at a concentration of $0.20 \mu M$ (data not shown). In addition, increasing the annealing temperature to $64^{\circ} \mathrm{C}$ further reduced the incidence of nonspecific background bands. Although the increased $T_{\mathrm{A}}$ slightly reduced the sensitivity of the assay with respect to the F2/B5 primer combination (data not shown), sensitivity was not affected when using the F1/B5 primer combination. Consequently, the F1/B5 primer combination was chosen as the best universal primer pair and it is these primers that are used in all subsequent PCR assays for MMLV-based proviruses.

\section{Sensitivity and specificity of the F1/B5 $\Psi$ primers}

Figure $3 \mathrm{~A}$ shows the results of an experiment to test the absolute sensitivity of the F1/B5 $\Psi$ primer combination. This primer pair was tested against a two-fold dilution series of $\beta 7$

\begin{tabular}{llll}
\hline & $F 1$ & $F 2$ & $F 3$ \\
\hline B1 & XP, IP & XP & NP \\
B2 & XP & XP & NP, XP \\
B3 & NP & XP, NP & NP, IP \\
B4 & XP & IP & NP, XP \\
B5 & OK & OK & NP \\
\hline
\end{tabular}
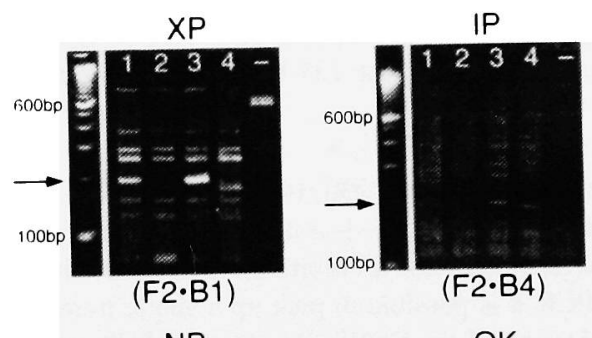

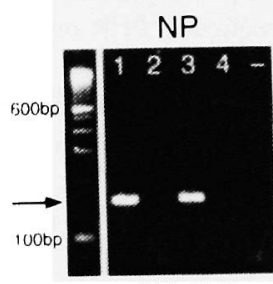

$(\mathrm{F} 3 \cdot \mathrm{B} 1)$
$(\mathrm{F} 2 \cdot \mathrm{B} 4)$

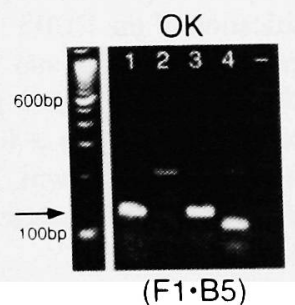

FIG. 2. Matrix analysis of $\Psi$ primer combinations. A complete matrix of 15 possible primer combinations was investigated for the ability to amplify $\Psi$ packaging sequence DNA. Results are summarized in table format and representative examples of each possible outcome are shown: XP, excessive nonspecific bands; IP, insufficient PCR product formation; NP, no PCR product formation with LXSN/LNL6-based vectors; and OK, PCR product of the expected size with little or no nonspecific bands. For each example, lanes $1,2,3$, and 4 are the result of amplifying 250 cell equivalents of $\beta 7$ ( $\Psi$ positive), KG-1a ( $\Psi$ negative), SV29 ( $\Psi$ positive), and Sp6- $\gamma(\Psi$ positive) cells; lane -, negative PCR buffer control. An arrow indicates the size of the expected PCR product based on the MMLV sequence (see Fig. 1). 


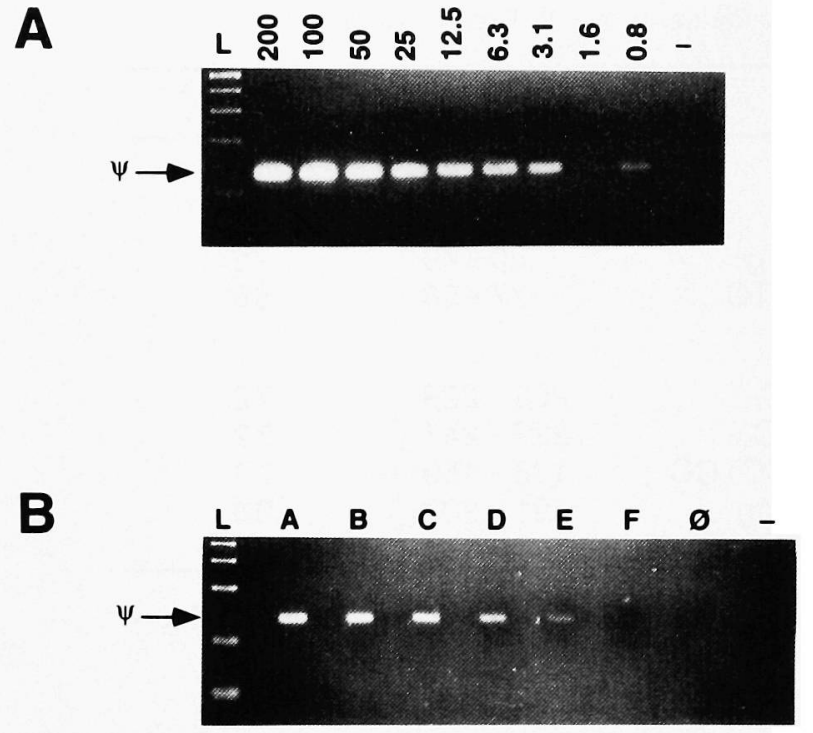

FIG. 3. $\Psi$ PCR sensitivity. A. Absolute sensitivity of the primers F1/B5 in a 40-cycle PCR. The primer pair was tested against a two-fold dilution series of $\beta 7$ ( $\Psi$ positive) cell lysates at $200,100,50,25,12.5,6.3,3.1,1.6$, and 0.8 cell equivalents ( - , negative PCR buffer control). B. Detection capability of the F1/B5 $\Psi$ primers in a 30 -cycle bulk PCR assay. Bulk PCR controls were made by adding $\mathrm{KG}-1$ a cells ( $\Psi$ negative) to a two-fold dilution series of SV29 ( $\Psi$ positive) cells. Lysates A through F contain $10,5,2.5,1.3,0.6$, and $0.3 \%$ SV29 cells, respectively. Lysate $\varnothing$ contains $100 \% \mathrm{KG}-1$ a cells. The total number of cell equivalents per PCR is 2,500 . For $\mathrm{A}$ and $\mathrm{B}, \mathrm{L}$ is a 100 -bp ladder $(500,400,300,200,100,50 \mathrm{bp})$; an arrow indicates the position of the 134-bp $\Psi$ PCR product.

( $\Psi$ positive) cell lysates at $200,100,50,25,12.5,6.3,3.1,1.6$, and 0.8 cell equivalents ( - is a negative PCR buffer control). PCR amplification of this dilution series suggested that with the 40 -cycle PCR it is possible to pick up a single transduced cell by amplification of the F1/B5 $\Psi$ sequence. PCR on single $\beta 7$ cells deposited by FACS into individual wells of a Terasaki plate verified that the F1/B5 $\Psi$ primer combination had singlecell detection sensitivity in a 40 -cycle reaction at a frequency of $50 \%$ (4/8; data not shown). By comparison, the 250-bp $\beta$ globin PCR product was detectable at a level of $8 \%(1 / 12$; data not shown).

Figure 3B compares the sensitivity of the F1/B5 $\Psi$ primers when SV29 ( $\Psi$ positive) cells are in a background of KG-1a ( $\Psi$ negative) cells, thus simulating the conditions of a bulk PCR to estimate percent transduction immediately following a transduction protocol. The absolute number of cell equivalents for each dilution in the series was 2,500 cells. To obtain a dose-response in product yield, this PCR was reduced to 30 cycles total. Sensitivity is down to $0.6 \%$ positive cells (dilution E) for the SV29 dilution series.

To demonstrate the efficacy of the F1/B5 $\Psi$ primers in detecting transduced methylcellulose colonies when these colonies are pooled, five colonies growing in methylcellulose were pooled and processed for the PCR. Three different lysates were analyzed which had different ratios of nontransduced and transduced colonies: $4: 1,3: 2$, and 2:3 (KG-1a colonies: $\beta 7$ colonies). The data presented in Fig. 4A demonstrate that a single transduced colony is detectable even when present in a background of four nontransduced colonies, indicating that the assay has sufficient sensitivity to be effective when pooling colonies is required.

There has been some concern that trace amounts of methylcellulose medium, which can contaminate the lysate during the processing of hematopoietic stem/progenitor cells, can interfere with the PCR (Bregni et al., 1992). Figure 4B shows the results of an experiment to determine the effect of residual methylcellulose medium on $\Psi$ PCR sensitivity in a lysate consisting of $\beta 7$ cells ( $\Psi$ positive) in a background of KG-1a cells ( $\Psi$ negative). Samples in lanes $1-6$ all contain $375 \mathrm{KG}-1$ a cell equivalents. Samples in lanes 1 and 4, 2 and 5, and 3 and 6 contain $125,62.5$, and $12.5 \beta 7$ cell equivalents, respectively. Samples in lanes 4-6 were processed with the addition of methylcellulose medium, while samples in lanes 1-3 were processed without the addition of methylcellulose medium. The similarity in product formation seen in lanes 1-3 versus lanes 4-6 indicates that the sensitivity of the primer combination presented in this report does not appear to be affected by trace amounts of methylcellulose medium carried over from the processing of pooled methylcellulose colonies for the PCR. In contrast to our results with the $\Psi$ primers, we have found that residual methylcellulose medium in the PCR can dramatically reduce the sensitivity of certain primer pairs that are used to detect transduction by MMLV-based vectors. In Fig. 5A, we show that a primer pair specific for the MFG-lac $Z$ vector is quite sensitive to contamination of the PCR by methylcellulose medium. In addition to having a reduced signal at high template number (50-100 copies/reaction), these primers lose their ability to amplify the template DNA at low copy numbers ( $\leq 25$ copies/reaction) (Fig. $5 \mathrm{~A}$ ). The effect of contaminating methylcellulose medium on the robustness of the PCR is also apparent when analyzing transduced colonies where we found that the MFG-lacZ-specific primers yield a relatively weak amplification signal (Fig. 5B) relative to the $\Psi$ primers in a multiplex reaction (Fig. 6A).

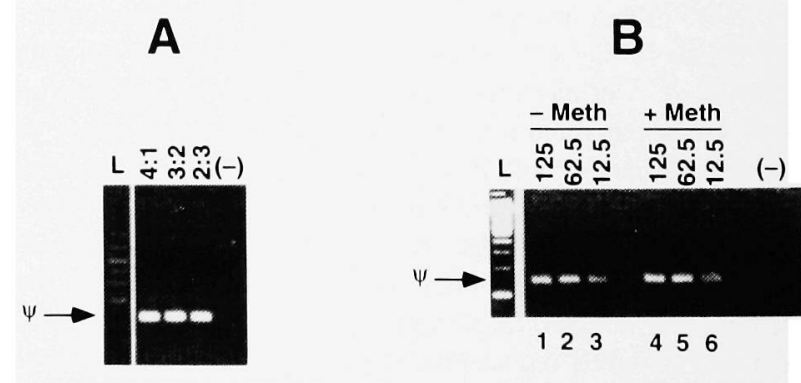

FIG. 4. The effect of residual methylcellulose medium in the PCR. A. $\beta 7$ ( $\Psi$ positive) and KG-1a ( $\Psi$ negative) colonies were pooled and processed for the PCR according to the following ratio- $4: 1,3: 2$, and $2: 3 \mathrm{KG}-1 \mathrm{a}: \beta 7$ colonies. B. Results of an experiment to determine the effect of residual methylcellulose medium on PCR sensitivity in a lysate consisting of $\beta 7$ cells in a background of KG-1a cells. Samples in lanes $1-6$ all contain $375 \mathrm{KG}-1$ a cells. Samples in lanes 1 and 4, 2 and 5, and 3 and 6 contain $125,62.5$, and $12.5 \beta 7$ cells, respectively. Samples in lanes 4-6 were processed with the addition of methylcellulose medium, while samples in lanes $1-3$ were processed without the addition of methylcellulose medium. 


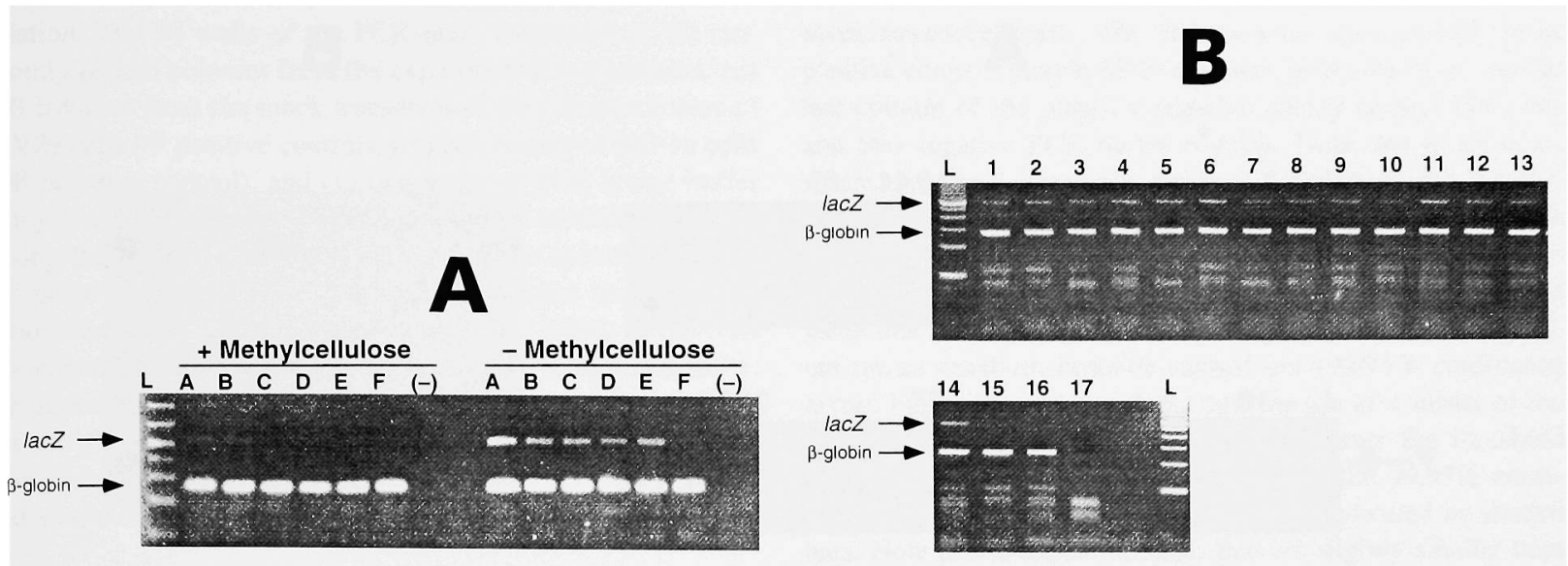

FIG. 5. A. The effect of residual methylcellulose on the PCR amplification of $\beta 7$ cells using the lacZ primers, $L Z 4927$ and LZ5466. Samples A-F represent two-fold dilutions of the lacZ-transduced cell line, $\beta 7(100,50,25$, 12, 6, and 3 cell equivalents, respectively; (-) is a negative PCR buffer control; L is a 100-bp ladder). These cells were processed for the PCR in a similar fashion to the standards mentioned in the text (see Materials and Methods), with and without the addition of 5\% methylcellulose medium (final concentration) in the PCR cell lysing buffer. B. PCR primer robustness when analyzing single colonies of clonogenic cells growing in methylcellulose medium. Single colonies of $\beta 7$ cells growing in methylcellulose medium were picked and processed for the PCR as mentioned in the text. Colony lysates (\#1-16) were amplified in a multiplex PCR (lacZ and $\beta$-globin) and then visualized by electrophoresis in an ethidium bromide containing gel (lanes 15 and 16 represent colonies of lacZnegative KG-1a cells, and lane 17 is a negative PCR buffer control; L is a 100-bp ladder).

\section{Direct lysate PCR from single methylcellulose colonies}

In Figure 6 we demonstrate that the single colony direct lysis PCR protocol presented in this report can be used reliably to detect transduced human cells in clonogenic methylcellulose assays. Figure 6A is the ethidium bromide-stained gel of the single target PCR ( $\Psi$ only, top row) and multiplex PCR ( $\Psi$ and $\beta$-globin, bottom row) for single methylcellulose colonies harvested as described above. All $\beta 7$ and SV29 colonies are positive for both the $\Psi$ sequence and $\beta$-globin, whereas the single

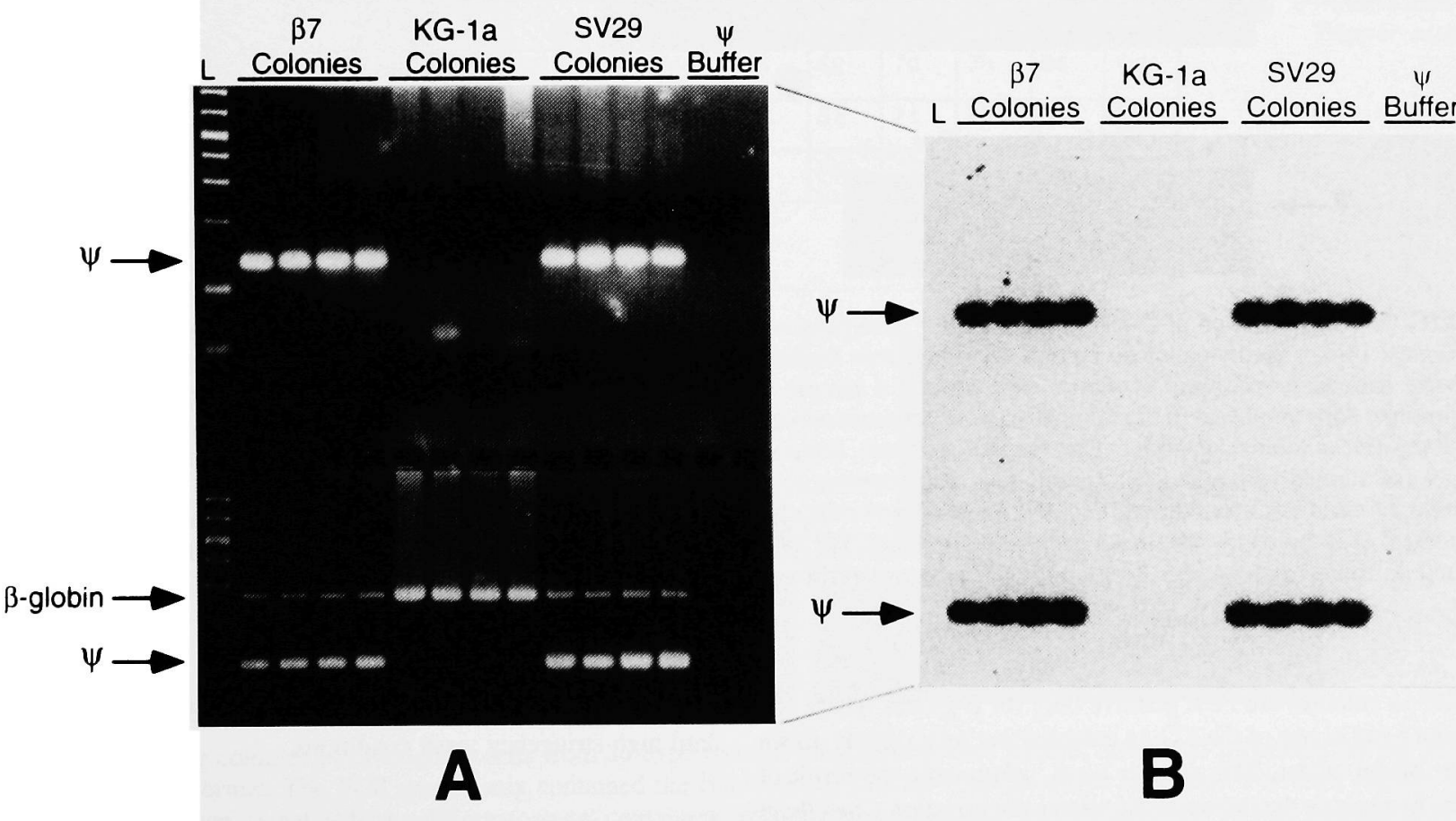

FIG. 6. Direct lysate PCR from single methylcellulose colonies of $\beta 7$ ( $\Psi$ positive) and KG-1a ( $\Psi$ negative) cells. A. Ethidium bromide-stained agarose gel of a PCR using only the $\Psi$ primers F1/B5 (top row), or the $\Psi$ and $\beta$-globin primers (multiplex PCR, bottom row). An arrow indicates the position of the 134-bp $\Psi$ PCR product and/or the 250 -bp $\beta$-globin product. $\Psi$ Buffer, negative PCR control of the buffer used to process the colonies; L, 100-bp ladder. B. Southern blot of the agarose gel in A hybridized to the $\Psi$ PCR product internal probe, BK29. 

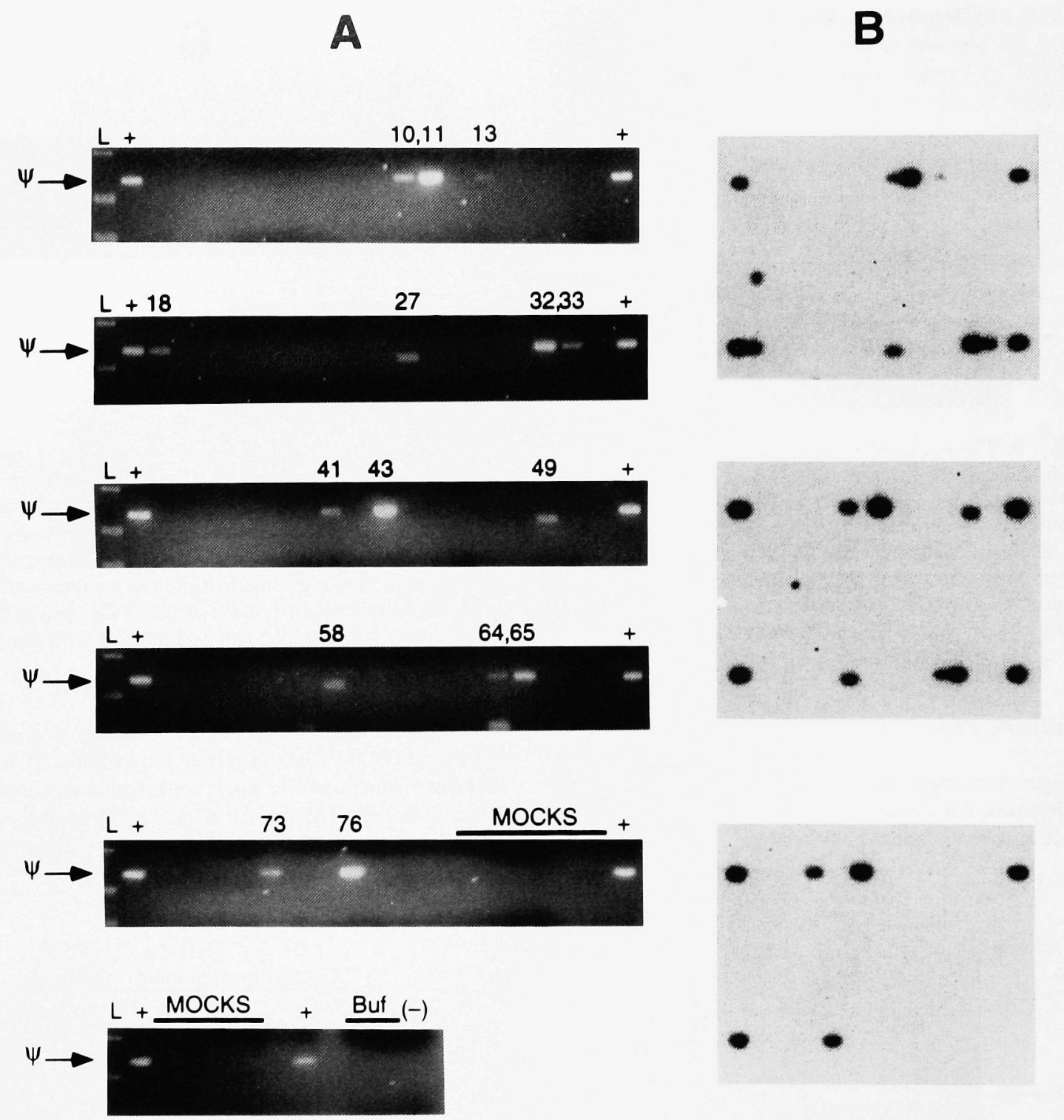

FIG. 7. Transduction of CD34 ${ }^{+}$Thy $-1^{+} \mathrm{Lin}^{-}$stem/progenitor cells isolated from cytokine-mobilized human peripheral blood. Eighty 14-day methylcellulose colonies derived from hematopoietic stem/progenitor cells growing in methylcellulose medium were harvested and lysed in the 96-well format; a sample of the lysate from each colony was amplified using the F1/B5 $\Psi$ primers. Also amplified in the same plate were 10 hematopoietic colonies of mock-transduced cells, three positive controls (SV29, $\Psi$ positive colonies), and three negative PCR controls. For post-PCR analysis, $15 \mu$ l of the reaction was loaded onto a $4 \%$ agarose gel and stained with ethidium bromide (A). The numbers above each lane indicate only those samples that were considered positive by ethidium bromide staining and Southern hybridization with the internal probe BK29 (B). L, 100-bp ladder; + , positive control (134-bp band) loaded on each side of the gel. For each panel, an arrow indicates the location of the F1/B5 $\Psi$ PCR product. A. Ethidium bromide-stained gel. B. Southern hybridization of each gel with the internal probe, BK29.

KG-1a colonies are PCR positive only for $\beta$-globin. There is a faint band in one of the KG-1a colonies that runs slightly above the 50-bp ladder. This smaller band, presumably the result of the increase in the incidence of primer dimerization when there is no specific primer template available, is the result of nonspecific amplification (as shown in Fig. 6B) and is easily distinguishable from the 134-bp target-specific $\Psi$ PCR product. Figure $6 \mathrm{~B}$ is an 18-hr exposure after hybridization of the southern blot with the end-labeled internal probe BK29. Only the $\Psi$ - specific PCR product remains hybridized to BK29 after standard high-stringency wash conditions.

\section{Experimental transduction data}

The human CD34+ ${ }^{+}$Thy- $1^{+} \mathrm{Lin}^{-}$cells were sorted (Becton Dickinson, FACStar Plus), transduced with a Moloney-based LMTNL retroviral vector, and plated in methylcellulose medium to assess transduction of the stem/progenitor cell pop- 
ulation. The 96 wells of the PCR plate contained: (i) 80 randomly picked colonies from the experimental transduction, (ii) 10 colonies from the mock transduction, (iii) three colonies of SV29 cells ( $\Psi$ positive controls, (iv) one colony of KG-1 a cells ( $\Psi$ negative control), and (v) two wells of PCR lysing buffer (negative PCR control) (Fig. 7A). Southern hybridization data using the internal probe, BK29, verifies the specificity of the $\Psi$ positive samples (Fig. $7 \mathrm{~B}$; positive samples are numbered above the lane). For this experiment, 19\% (15/80) of the cells clonogenic in methylcellulose medium were transduced, as determined by amplification of the $\Psi$ PCR product, whereas none of the 10 mock colonies was positive, further indicating that this assay can be carried out in a 96-well format without aerosol contamination of negative samples by positive samples.

\section{TaqMan fluorescence-based post-PCR detection assay}

In Fig. 8 we show the results of an experiment to compare the sensitivity and specificity of an ethidium bromide-stained gel versus the TaqMan fluorescence assay. Figure $8 \mathrm{~A}$ displays the results for the entire plate. Samples \#1-80 represent single methylcellulose colonies from the experimental transduction, whereas samples \#81-90 are single methylcellulose colonies of mock-transduced cells. The 96-well plate also includes three positive controls (single SV29 colonies; indicated by a + in the last column of the plate), a negative colony control (KG-1a), and two negative PCR buffer controls. Note that in all cases where there is a detectable ethidium bromide-stained band of the appropriate size, the TaqMan assay reports a positive result (sample $\Delta \mathrm{RQ}>$ threshold $\Delta \mathrm{RQ}$ ). There are even three cases (\#'s 18, 27, 54) for which the TaqMan assay reports a positive result that is not detectable from loading $10 \mu \mathrm{l}$ of the PCR product on an ethidium bromide-stained gel $(99.95 \%$ confidence level). Figure $8 \mathrm{~B}$ shows a direct comparison of a subset of the samples (\#55-90). The dashed line represents the threshold $\Delta \mathrm{RQ}$ above which samples are positive at the $99.95 \%$ confidence level. TaqMan-positive samples are indicated by shaded bars. Note that nonspecific bands that are slightly smaller than the 134-bp PCR product (sample \#'s 59, 77), primer-dimers (visible as a band at the bottom of each lane), and other artifacts of the PCR are not positive with the TaqMan assay and attest to the specificity of the fluorescent probe.

In general, the detection capability of the TaqMan assay depends largely on the design of the fluorescently labeled probe (see Perkin-Elmer regarding guidelines for probe design) and the efficient amplification of the target DNA with the PCR

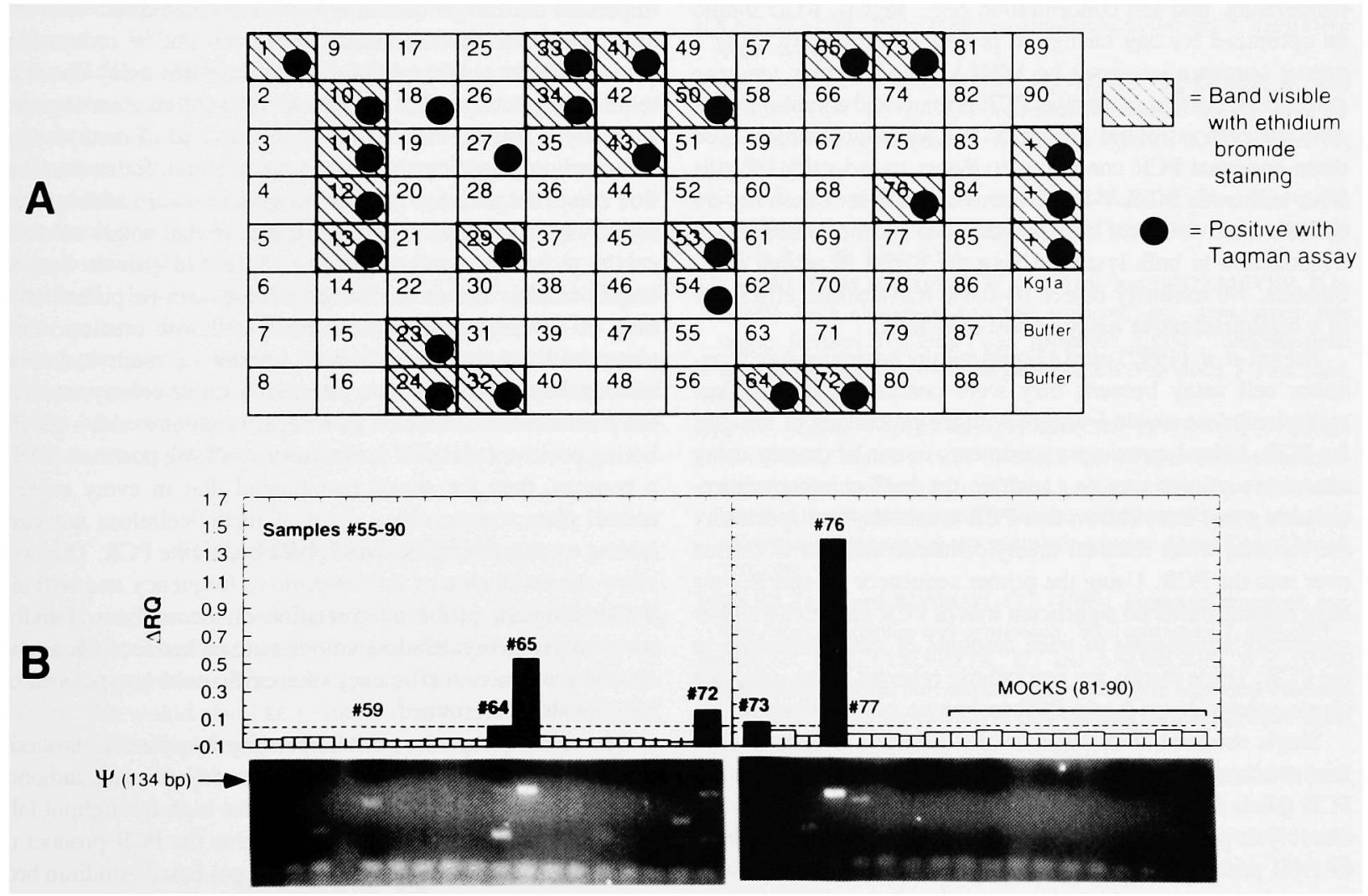

FIG. 8. Single colonies of clonogenic cells from an experimental transduction were picked, lysed, and processed for the PCR in the 96-well format. The PCR master mix contained the fluorescently labeled TaqMan probe (see text). For each sample, 10 $\mu \mathrm{l}$ of the PCR was visualized on a 4\% agarose gel containing ethidium bromide, while the remaining $50 \mu 1$ was transferred to a fluorescent spectrometer plate reader. A. Samples \#1-80 represent colonies derived from hematopoietic stem/progenitor cells exposed to retroviral supernatant, samples \#81-90 are colonies of mock-transduced cells. +, Single SV29 ( $\Psi$ positive) colonies; KG-1a, single $\Psi$ negative colony; Buffer, negative PCR control. B. Direct comparison of an ethidium bromide-stained gel and the TaqMan assay for a subset of the samples (\#55-90). The dashed line represents the threshold $\Delta \mathrm{RQ}$ above which samples are positive at the $99.95 \%$ confidence level. TaqMan-positive samples are indicated by shaded bars. 
primer pair. Using the Fl/B5 primers and the TaqMan probe designed for the $\Psi$ PCR product, we have compared the ethidium bromide staining detection capability versus TaqMan fluorescence from a total of four separate amplifications (full 96well plates, as above; data not shown) and conclude that the results presented in Fig. 8 are indeed representative of the assay sensitivity and specificity. We were consistently able to detect a TaqMan-positive sample ( $99.95 \%$ confidence level) in all cases where there was at least a faint ethidium bromide-stained band. It should be noted, however, that for each of the four experiments, we consistently used 10 no-template controls to calculate the threshold $\triangle \mathrm{RQ}$. Because the threshold $\triangle \mathrm{RQ}$, and consequently a TaqMan-positive sample, is a function of the statistical power of the assay, it is possible that analyzing fewer no-template controls could increase the threshold $\Delta \mathrm{RQ}$ and reduce the ability to statistically distinguish the faint positive samples from the no-template controls.

\section{DISCUSSION}

The efficient amplification of a PCR target usually requires that reaction parameters be tailored for the specific conditions of the assay. Variables such as primer concentration, annealing temperature, and salt concentration (e.g., $\mathrm{MgCl}_{2}, \mathrm{KCl}$ ) should be optimized for any change in primer sequence. By using a primer sequence universal for MMLV-based vectors, we have avoided the need to reoptimize PCR primers and conditions specific for each retroviral construct. We have successfully used these universal PCR conditions to detect transduction of cells from numerous MMLV-based retroviral vectors. Likewise, we can use a universal set of PCR standards for the estimation of transduction in bulk lysates. Using the F1/B5 $\Psi$ primer combination, we routinely detect $10-0.6 \%$ transduction efficiency in a semiquantitative assay $(2,500$ cells total).

Bregni et al. (1992) used a liquid culture hematopoietic progenitor cell assay because they were concerned that residual methylcellulose would interfere with the processing of samples for PCR. Indeed, previous experiments in our laboratory using alternative primer sites (e.g., within the lac $Z$ or neomycin-resistance gene) have shown that PCR sensitivity and specificity are reduced when residual methylcellulose medium is carried over into the PCR. Using the primer sequences F1 and B5, we have demonstrated no significant loss of PCR sensitivity and/or specificity attributable to trace amounts of methylcellulose in the PCR. These results are particularly relevant when using the single-colony direct lysate PCR technique presented above.

Single colonies of clonogenic cells growing in methylcellulose medium (Brandt et al., 1988) are routinely analyzed by PCR (Dick et al., 1991). Cassel et al. (1993) have even used a direct lysis protocol where single colonies are picked and lysed in $\mathrm{H}_{2} \mathrm{O}$ prior to $\mathrm{PCR}$ analysis. However, most single-colony protocols involve multiple rinsing steps (Ramaswamy et al., 1989; Rill et al., 1992; Lu et al., 1993) and even DNA extractions (Lu et al., 1994). The single-colony direct lysate technique presented here involves no rinsing of the colonies, and the lysate is used directly in the PCR reaction without protein extraction or DNA precipitation.

The greatest advantage of single-colony direct lysate PCR analysis carried out in a 96-well format is the reduction in pro- cessing time. Methylcellulose colonies are harvested directly into the PCR lysing buffer, thereby omitting the PBS rinse step. Decreased handling of the lysate further reduces the potential for contamination and sampling error due to multiple pipetting steps. These time-saving steps allow processing of greater numbers of samples, while utilizing the 96 -well format permits the use of multichannel pipetters to expedite the addition of reagents, lysates, etc. Furthermore, many popular thermal cyclers with 96well formats easily accommodate small PCR reaction volumes, leading to a substantial decrease in the cost of reagents.

Aside from expediting the PCR set-up, the single-colony direct lysate technique yields a more accurate estimate of transduction frequency. When colonies are pooled, calculating the transduction frequency will almost always be an underestimate since when a sample is PCR positive one can never be absolutely certain if single or multiple colonies were transduced. In addition, pooling five colonies for PCR analysis frequently results in taking up 10-12 $\mu \mathrm{l}$ of methylcellulose media. Large volumes of methylcellulose may not only interfere with the PCR, but also increase the odds of inadvertently collecting stray cells that are not part of the colony being harvested. These stray cells could lead to detectable levels of PCR product and an overall positive result for that sample. Rather than design a less sensitive assay, we feel that the sensitivity of this assay gives it an important advantage over less sensitive techniques. The frequency of false, nonclonogenic, positives can be reduced by plating cells at a reduced density. Because this assay does not require the pooling of colonies, fewer total colonies are required for analysis and the harvesting of only $1-3 \mu$ l of methylcellulose medium significantly reduces the potential for contamination due to the presence of nonclonogenic cells. In addition, the sensitivity of this assay is an advantage in that single colonies can be picked for analysis prior to 14 days of growth. For example, smaller and more distinct colonies can be picked after only 10-12 days of growth in methylcellulose medium; this, along with the extremely small amount of methylcellulose medium aspirated in the harvesting of a single colony, reduces the potential contamination of a negative colony with a neighboring positive colony. If the frequency of false positives is still a concern, then we would recommend that in every experimental plate representative areas of methylcellulose not containing a colony are picked and processed in the PCR. This will allow the estimation of a false-positive frequency and will aid the investigator in the interpretation of the analysis. Finally, when single methylcellulose colonies are picked for PCR analysis, the transduction efficiency of specific colony types can be more readily determined.

The technique presented here permits the effective processing of a large number of samples in the conventional, and convenient, 96-well format; however, for the high-throughput laboratory, it can become tedious to examine the PCR product of such a large number of samples using a gel-based ethidium bromide-staining detection system. It follows that an alternative detection system such as a fluorescence-based post-PCR detection assay, which can take advantage of the 96-well format of the PCR, would be a step forward in expediting an already improved and efficient assay.

We have recently completed experiments using the TaqMan assay (Perkin-Elmer Corporation). This system of PCR product detection uses the $5^{\prime} \rightarrow 3^{\prime}$ exonuclease activity of Thermus 
aquaticus DNA polymerase (Holland et al., 1991) to cleave a fluorescently labeled probe during each round of PCR amplification (Lee et al., 1993). Post-PCR product analysis merely involves placing the 96-well tray/retainer assembly containing the open PCR reaction tubes into the specially designed fluorescent plate reader, and within minutes, the spectrophotometer reads the fluorescence signal from all 96 wells and summarizes the results in spreadsheet format. Because the assay does not consume any part of the reaction volume, the samples can be saved and used for other purposes (e.g., gel verification). After examining a number of alternative detection systems for post-PCR analysis, we conclude that this system is extremely fast, convenient, and at least as sensitive as an ethidium bromide-based detection system when analyzing PCR product amplified with the F1/B5 $\Psi$ primers. Furthermore, the specificity of the internal probe makes a hybridization assay of PCR product unnecessary.

This study describes a sensitive assay system which takes advantage of the standard 96-well format to expedite the processing of single methylcellulose colonies. Assay sensitivity is dependent on PCR conditions optimized for the F1/B5 PCR primer pair that amplifies a region of the $\Psi$ packaging sequence of Moloney-based retroviruses. In addition, with some minor modifications in retroviral vector design, the assay can be used for more specialized applications. For example, if a short nucleotide linker (e.g., $50 \mathrm{bp}$ ) were added internal to the amplifiable region of the F1/B5 primers, then it would be possible to use the assay in a protocol designed to track two independently transduced populations of cells. Finally, it is important to keep in mind that when targeting the $\Psi$ packaging sequence alone, or any other appropriately sized PCR target in a retroviral vector, that a positive result does not necessarily imply an intact provirus; it is always possible that the gene of interest has been lost or has recombined. However, the strength of this assay is in its ability to allow generic detection of Moloney-based vectors. This PCR primer pair, along with the capability for more rapid screening of hematopoietic stem/progenitor colonies, is especially useful for the laboratory that is screening a number of different retroviral constructs for their transduction efficiency.

\section{ACKNOWLEDGMENTS}

We thank Sean Forestell and Richard Rigg for the LMTNL vector supernatant used in the experimental transduction, and Lishan Su and Maija Wessman for critical review of the manuscript. We would also like to thank Bob Blalock and Mitchell Kennedy for supplying the TaqMan probe and for their assistance with the TaqMan assay.

\section{REFERENCES}

ARMENTANO, D., YU, S-F., KANTOFF, P.W., VON RUDEN, T., ANDERSON, W.F., and GILBOA, E. (1987). Effect of internal viral sequences on the utility of retroviral vectors. J. Virol. 16, $1647-1650$.

BENDER, M.A., PALMER, T.D., GELINAS, R.E., and MILLER, D.A. (1987). Evidence that the packaging signal of Moloney Murine Leukemia virus extends into the gag region. J. Virol. 61, 1639-1646.
BONNEROT, C., ROCANCOURT, D., BRIAND, P., GRIMBER, G., and NICOLAS, J-F. (1987). A $\beta$-galactosidase hybrid protein targeted to nuclei as a marker for developmental studies. Proc. Natl. Acad. Sci. USA 84, 6795-6799.

BRANDT, J., BAIRD, N., LU, L., SROUR, E.F., and HOFFMAN, R (1988). Characterization of a human hematopoietic progenitor cell capable of forming blast colonies in vitro. J. Clin. Invest. 82, 1017. BREGNI, M., MAGNI, M., SIENA, S., DI NICOLA, M., BONADONNA, G., and GIANNI, A.M. (1992). Human peripheral blood hematopoietic progenitors are optimal targets of retroviral-mediated gene transfer. Blood 80, 1418-1422.

CASSEL, A., COTTLER-FOX, M., DOREN, S., and DUNBAR, C.E. (1993). Retroviral-mediated gene transfer into CD34-enriched human peripheral blood stem cells. Exp. Hematol. 21, 585-591.

DICK, J.E., KAMEL-REID, S., MURDOCH, B., and DOEDEN, S.M. (1991). Gene transfer into normal human hematopoietic cells using in vitro and in vivo assays. Blood 78, 624-634.

HOLLAND, P.M., ABRAM $\overline{S O N}$, R.D., WATSON, R., and GELFAND, D.H. (1991). Detection of specific polymerase reaction product by utilizing the $5^{\prime} \rightarrow 3^{\prime}$ exonuclease activity of Thermus aquaticus DNA polymerase. Proc. Natl. Acad. Sci. USA 88, 7276-7280.

HWU, P., SHAFER, G.E., TREISMAN, J., SCHINDLER, D.G., GROSS, G., COWHERD, R., ROSENBERG, S.A., and ESHAR, Z. (1993). Lysis of ovarian cancer cells by human lymphocytes redirected with a chimeric gene composed of an antibody variable region and the Fc receptor $\gamma$ chain. J. Exp. Med. 178, 361-366.

JOLLY, D. (1994). Viral vector systems for gene therapy. Cancer Gene Ther, 1, 51-64.

KOEFFLER, H.P., BILLING, R., LUSIS, A.J., SPARKES, R., and GOLDE, D.W. (1980). An undifferentiated variant derived from the human acute myelogenous leukemia cell line (KG-1). Blood 56, 265-273.

LEE, G.L., CONNELL, C.R., and BLOCH, W. (1993). Allelic discrimination by nick-translation PCR with fluorogenic probes. Nucleic Acids Res. 21, 3761-3766.

LU, L., XIAO, M., CLAPP, D.W., LI, Z-H., and BROXMEYER, H.E. (1993). High efficiency retroviral mediated gene transduction into single isolated immature and replatable $\mathrm{CD} 34^{+}$hematopoietic stem/progenitor cells from human umbilical cord blood. J. Exp. Med. 178, 2089-2096.

LU, M., MARUYAMA, M., ZHANG, N., LEVINE, F., FRIEDMANN, T., and HO, A.D. (1994). High efficiency retroviral-mediated gene transduction into $\mathrm{CD} 34^{+}$cells purified from peripheral blood of breast cancer patients primed with chemotherapy and granulocyte-macrophage colony-stimulating factor. Hum. Gene Ther. 5, 203-208.

MILLER, D.A., and ROSMAN, G.J. (1989). Improved retroviral vectors for gene transfer and expression. BioTechniques 7, 980-990.

MORGAN, R.A., CORNETTA, K., and ANDERSON, W.F. (1990) Applications of the polymerase chain reaction in retroviral-mediated gene transfer and the analysis of gene-marked human TIL cells. Hum. Gene Ther. 1, 135-149.

NOLAN G.P., FIERING, S., NICOLAS, J-F., and HERZENBERG, L.A. (1988). Fluorescence-activated cell analysis and sorting of viable mammalian cells based on $\beta$-D-galactosidase activity after transduction of Escherichia coli lacZ. Proc. Natl. Acad. Sci. USA 85, 2603-2607.

RAMASWAMY, N., TARE, N.S., BENJAMIN, W.R., and GUBLER, U. (1989). A sensitive technique to monitor gene transfer and expression in bone marrow stem cells. Exp. Hematol. 17, 832-835.

RILL, D.R., BUSCHLE, M., FOREMAN, M.K, BARTHOLOMEW, C., MOEN, R.C., SANTANA, V.M., IHLE, J.M., and BRENNER, M.K. (1992). Retrovirus-mediated gene transfer as an approach to analyze neuroblastoma relapse after autologous bone marrow transplantation. Hum. Gene Ther. 3, 129-136. 
RYCHLIK, W. (1993). Selection of primers for polymerase chain reaction. In Methods in Molecular Biology, Vol. 15: PCR Protocols, Current Methods and Applications. B.A. White, ed. (Humana Press, Inc., Totowa, NJ) pp. 31-40.

SAIKI, R.K. (1989). Design and optimization of the PCR. In $P C R$ Technology: Principles and Applications for DNA Amplification. H.A. Erlich, ed. (Stockton Press, New York) pp. 7-16.

SAMBROOK, J., FRITSCH, E.F., and MANIATIS, T. (1989). Molecular Cloning: A Laboratory Manual, 2nd ed. (Cold Spring Harbor Laboratory Press, Cold Spring Harbor, NY).
Address reprint requests to: Dr. William G. Kerr Department of Molecular and Cellular Engineering Institute for Human Gene Therapy University of Pennsylvania Medical Center 3400 Spruce Street (M6. 40 Maloney)

Philadelphia, PA 19104-4283

Received for publication July 27, 1995; accepted after revision October 27, 1995. 


\section{This article has been cited by:}

1. Farastuk Bozorgmehr, Stefanie Laufs, Stephanie E. Sellers, Ingo Roeder, Walter J. Zeller, Cynthia E. Dunbar, Stefan Fruehauf. 2007. No Evidence of Clonal Dominance in Primates up to 4 Years Following Transplantation of Multidrug Resistance 1 Retrovirally Transduced Long-Term Repopulating Cells. Stem Cells 25:10, 2610-2618. [CrossRef]

2. I. M. Mackay. 2004. Real-time PCR in the microbiology laboratory. Clinical Microbiology and Infection 10:3, 190-212. [CrossRef]

3. F. Tögel , N. Kröger , F. Korioth , B. Fehse , A.R. Zander . 2002. Molecular Methods for Detection and Quantification of Myeloma Cells after Bone Marrow Transplantation: Comparison between Real-Time Quantitative and Nested PCRMolecular Methods for Detection and Quantification of Myeloma Cells after Bone Marrow Transplantation: Comparison between Real-Time Quantitative and Nested PCR. Journal of Hematotherapy Stem Cell Research 11:6, 971-976. [Abstract] [PDF] [PDF Plus]

4. Fusayuki Omori , Tarja Juopperi , Chi-Kin Chan, Yung-Nien Chang, Sandrina Phipps, Shaherose Nanji , Yongjun Zhao , A. Keith Stewart, Ian D. Dube . 1999. Retroviral-Mediated Transfer and Expression of the Multidrug Resistance Protein 1 Gene (MRP1) Protect Human Hematopoietic Cells from Antineoplastic DrugsRetroviral-Mediated Transfer and Expression of the Multidrug Resistance Protein 1 Gene (MRP1) Protect Human Hematopoietic Cells from Antineoplastic Drugs. Journal of Hematotherapy Stem Cell Research 8:5, 503-514. [Abstract] [PDF] [PDF Plus]

5. Greg J. Towers, Daniel Stockholm, Valérie Labrousse-Najburg, Frederique Carlier, Olivier Danos, Jean-Christophe Pagès. 1999. One step screening of retroviral producer clones by real time quantitative PCR. The Journal of Gene Medicine 1:5, 352-359. [CrossRef]

6. A. Keith Stewart, D. Robert Sutherland, Shaherose Nanji, Yongjun Zhao , Carolyn Lutzko , Rakash Nayar, Brian Peck , Christine Ruedy, Gary Mcgarrity , John Tisdale, Ian D. Dube . 1999. Engraftment of Gene-Marked Hematopoietic Progenitors in Myeloma Patients after Transplant of Autologous Long-term Marrow CulturesEngraftment of Gene-Marked Hematopoietic Progenitors in Myeloma Patients after Transplant of Autologous Long-term Marrow Cultures. Human Gene Therapy 10:12, 1953-1964. [Abstract] [PDF] [PDF Plus] 